\title{
Ring Gear Deformation and Its Controlling Method of Heavy Duty Ma- chine Tool Worktable
}

\author{
Jiang Bin ${ }^{*}$, Sun Bin, Zhao Jiaxue and Zhao Jiao
}

\author{
National \& Local United Engineering Laboratory of High Efficiency Cutting and Tools, Harbin University of Science \\ and Technology, Heilongjiang, Harbin, 150080, P.R. China
}

\begin{abstract}
According to the effect of ring gear assembly on the transmission and the positioning accuracy of heavy duty machine tool worktable, the deformation field of thin-walled ring gear under the effect of press fit force was analyzed. Under the condition of inhomogeneous deformation of ring gear assembly, the force and the coincidence degree in the meshing of the gears and ring gear were utilized to research the deformation of meshing tooth surface and its influence on the meshing accuracy of ring gear, and put forward the assembly process design method for controlling the non-uniform deformation of ring gear. In addition, the experiences of ring gear assembly and worktable precision detection were utilized to confirm the validity of the method. The results showed that the precision of worktable positioning and repeatability positioning meet the design requirements of CXK5463 gantry-moving type turn-milling machining center.
\end{abstract}

Keywords: Assembly deformation, Heavy duty machine tool, Meshing tooth surface, Worktable, Ring gear.

\section{INTRODUCTION}

The heavy duty machine tool usually has many functions such as milling, boring and turning. Through the worktable functional transformation interlock technology, except for the mounting surface, the multiple surfaces of part can be processed. As a result, the worktable of heavy-duty machine tool should not only have the large carrying capacity and high deformation-resistance ability, but also high accuracy of positioning and repeatability positioning [1].

The rotation motion and indexing motion of worktable are mainly realized with that the worktable ring gear is turned by the gears at the end of $\mathrm{C}$-axis box and the main transmission box. The ring gear which has thin-walled and whole structure, is assembled with worktable by screws. The deformation and its error of assembly directly determine the contact state between the ring gear and transmission gear, which has an important influence on the positioning accuracy and repeatability positioning of the worktable.

The assembly constraints and the load on the combined surface between the ring gear and the worktable directly determine ring gear deformation and influence the rotation movement and indexing accuracy of worktable [2, 3]. Studies have shown that there is a nonlinear proportional relationship between the load and the static stiffness of joint surface and there is a reverse relationship between the bolt loading times of joint surface and the tangential deformation on joint surface. The existing analysis method of force and deformation is not suitable for the requirement of heavy duty

*Address correspondence to this author at the School of Mechanical Engineering, Harbin University of Science and Technology, Heiliongjiang, Harbin, 150080, P.R. China; Tel: 13903611465; Fax: +86 045186390572 ; E-mail:13903611465@163.com machine tool high performance and the precision turningmilling [4-6].

At present, in order to reduce the assembly error of heavy duty machine tool, the error modeling, the error measurement and error compensation have been applied in machine assembly. The above method cannot only effectively solve the modeling problems of the whole machine tool error and recognize the static error, but also adopt dynamic error of each axis on the machine tool and the CNC system closedloop error compensation to reduce the machine tool errors. But the above methods do not effectively control the deformation and error in the assembly process of machine tool, meanwhile, it only compensates the whole error of machine tool in the small time-domain. So the methods are not applicable to solve accuracy declining problems in greater timedomain caused by the machine tool assembling error [7-10].

Because the worktable and the base of heavy duty machine tool mostly adopt divided structure, the decrease of straightness can be solved by combining grinding and the modification of spindle accuracy in the turning process. However, because the ring gear cannot be disassembled and tested frequently, the assembly method is unsuitable for solving the decline of the positioning accuracy and repeatability positioning accuracy caused by the deformation of ring gear assembly [11].

In this paper, aiming at the design requirement of the worktable rotation and the indexing precision of CXK5463 turning-milling machining center, and according to the ring gear structure and the assembly constraint relationship of worktable, the influence of the assembly deformation of ring gear on the meshing state of tooth surface is studied by the analysis of the force and coincidence degree of ring gear. The controlling method of assembly deformation of ring gear 


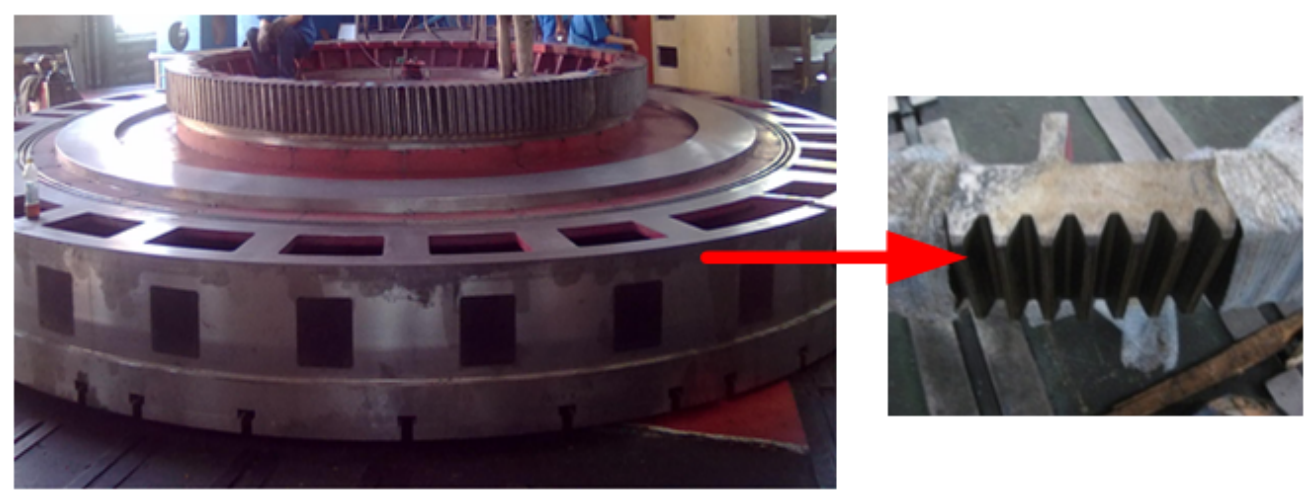

Fig. (1). Assembly relationship between ring gear and worktable.

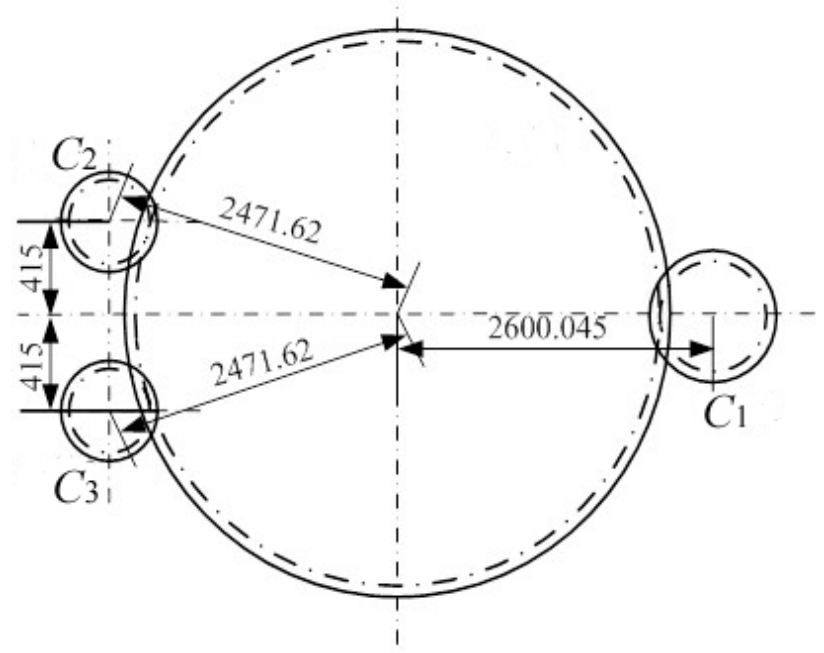

Fig. (2). Position relationship between the ring gear and the three gears.

is proposed to ensure the positioning accuracy and repeatability positioning accuracy of heavy duty machine tool worktable.

\section{ASSEMBLY CONSTRAINTS AND FORCE OF WORKTABLE RING GEAR}

The ring gear of worktable of CXK5463 turning-milling machining center adopts the integral structure, which material is ZG310-570 and the weight is $3520 \mathrm{~kg}$. The assembly relation among the ring gear, the worktable and the three gears is shown in Fig. (1) and Fig. (2).

There are two important joint surfaces between the ring gear and the worktable. One of them is a transition mating surface used for positioning the ring gear. Another junction surface is used for screw connection. The ring gear is assembled with the worktable by four pins and thirty two M36 $\times$ 100 screws.

The worktable rotation is achieved by the ring gear meshing with the drive gear and the indexing function of worktable is achieved by eliminating the meshing gap with the antibacklash gear pairs. The parameters of the ring gear and the other three gears are shown in Table $\mathbf{1 .}$
In the Table 1, under the maximum torque of $460 \mathrm{KN} \cdot \mathrm{m}$, the force acting on the ring gear and the coincidence of the meshing motion of the transmission gear are shown in Table 2.

In Table $2, F_{t}$ is the ring gear circumferential force. $F_{r}$ is the radial force. $F_{\alpha}$ is normal force. $f$ is the gear friction during motion. $\varepsilon_{\alpha}$ is the coincidence degree of the end face between the ring gear and drive gear $1 . \varepsilon_{\beta}$ is the longitudinal coincidence degree. $\varepsilon$ is the total coincidence.

Based on the assembly constraint relation among the ring gear, the worktable and the gears, the analysis of the assembly deformation of the ring gear is conducted with the coincidence calculation results of the meshing transmission among the ring gear and other gears, as shown in Fig. (3), Fig. (4) and Fig. (5).

Under the press-fit force of $20 \mathrm{KN}$, the inhomogeneous deformation phenomenon appears in the assembly process of the ring gear and the worktable. The diameter deviation of addendum circle caused with deformation along the $\mathrm{X}$ and $\mathrm{Y}$ directions, which leads to the displacement, which is caused 
Table 1. Structure parameters of the ring gear and the gears.

(1-1)

\begin{tabular}{|c|c|c|c|}
\hline Object & Material & Tooth Number & Normal Modulus (mm) \\
\hline \hline Gear 1 & 45 & 36 & 16 \\
\hline Gear 2、3 & $40 \mathrm{Cr}$ & 20 & 16 \\
\hline Ring gear & ZG310-570 & 288 & \multirow{2}{*}{16} \\
\hline
\end{tabular}

(1-2)

\begin{tabular}{|c|c|c|c|c|}
\hline Object & Pressure Angle & Helix Angle & Direction of Turning & Tooth Width (mm) \\
\hline \hline Gear 1 & $20^{\circ}$ & $4.5^{\circ}$ & Left-lateral & 210 \\
\cline { 1 - 4 } Gear 2、3 & $20^{\circ}$ & $4.5^{\circ}$ & Right-lateral & 160 \\
\cline { 1 - 2 } Ring gear & & & 200 \\
\hline
\end{tabular}

Table 2. Force and contact ratio of ring gear.

(2-1)

\begin{tabular}{|c|c|c|c|}
\hline$F_{t}(\mathbf{N})$ & $F_{r}(\mathbf{K N})$ & $F_{a}(\mathbf{K N})$ & $F_{n}(\mathbf{K N})$ \\
\hline \hline 199.04 & 72.67 & 15.66 & 212.47 \\
\hline
\end{tabular}

(2-2)

\begin{tabular}{|c|c|c|c|}
\hline$f(\mathbf{K N})$ & $\varepsilon_{\alpha}$ & $\varepsilon_{\beta}$ & $\varepsilon$ \\
\hline \hline 16.998 & 1.77 & 0.31 & 2.01 \\
\hline
\end{tabular}

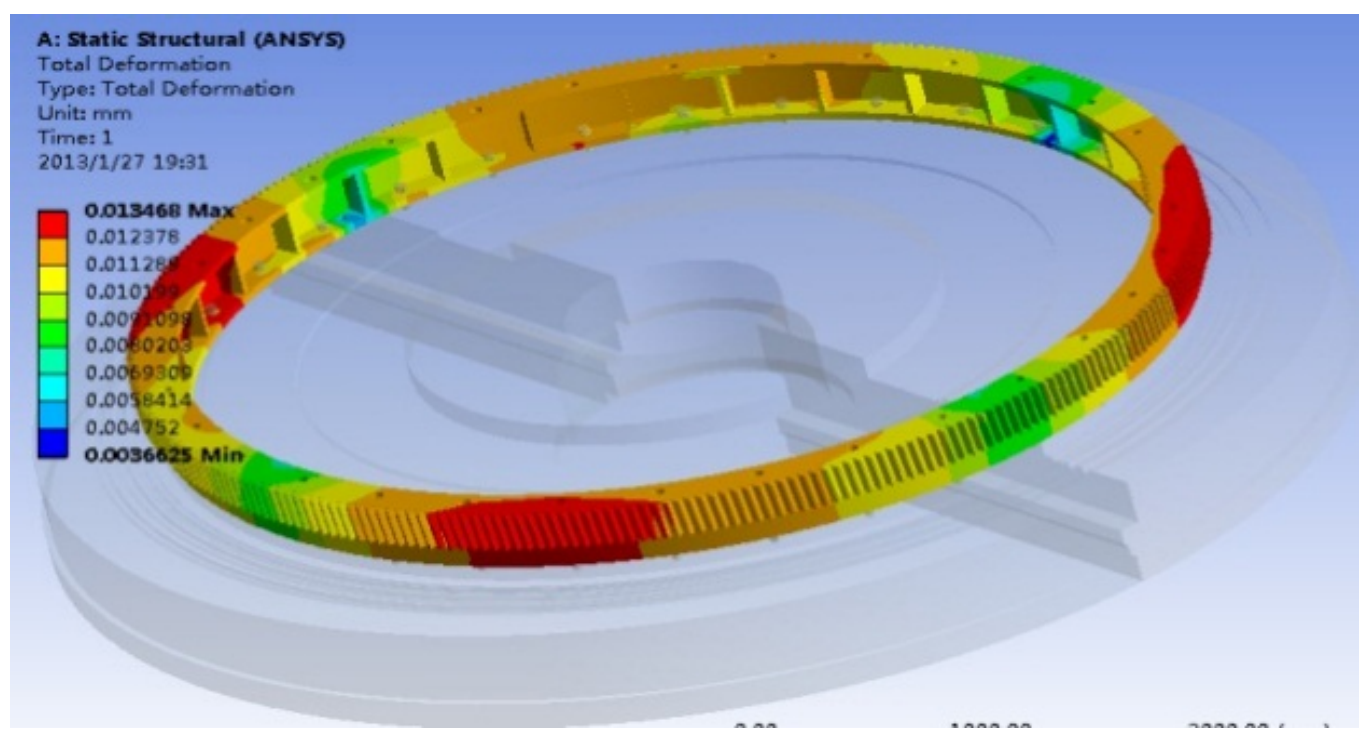

Fig. (3). Global deformation of ring gear. 


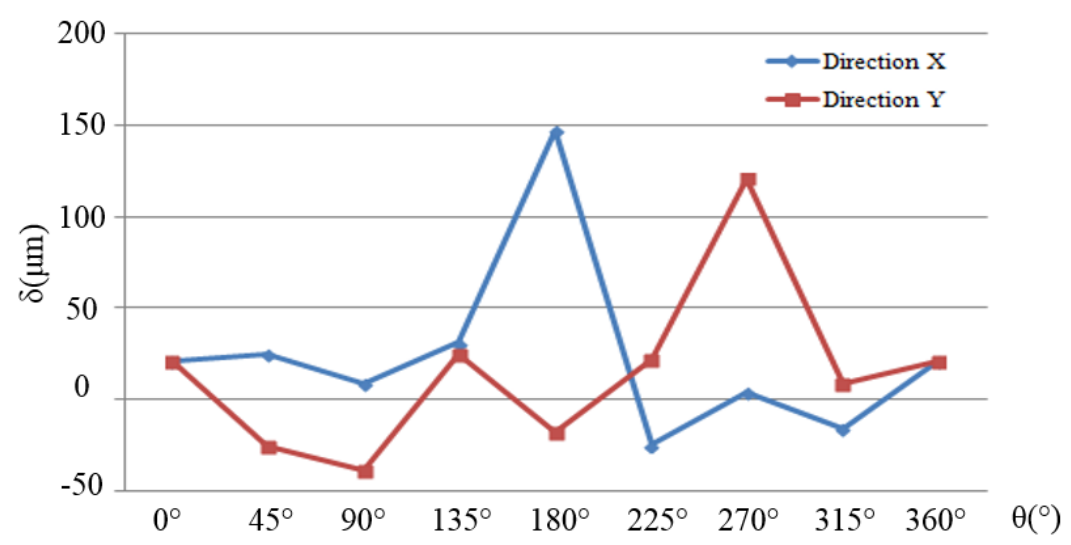

Fig. (4). Deformation in $\mathrm{X}$ and $\mathrm{Y}$ directions of ring gear.

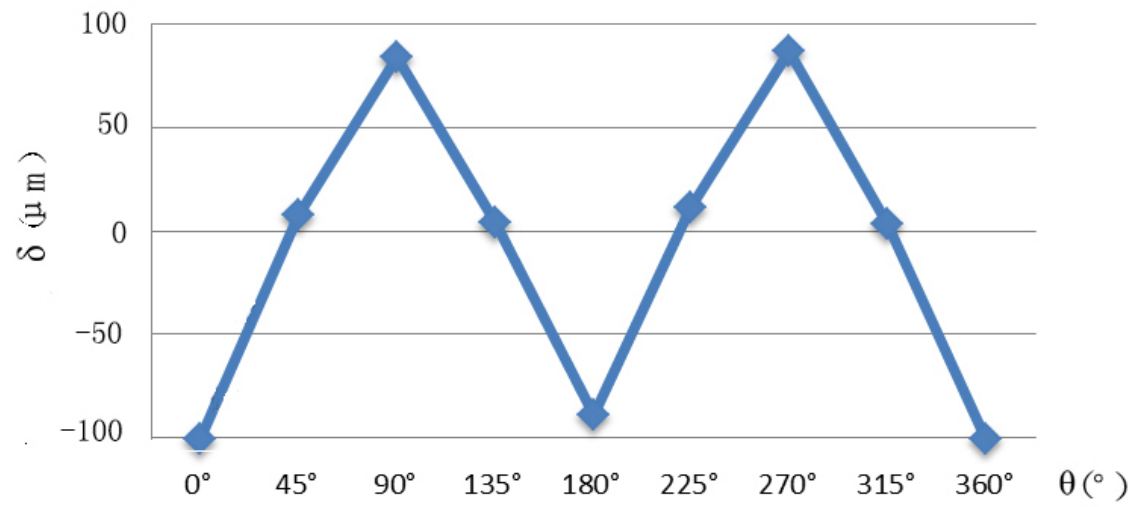

Fig. (5). Deformation in $\mathrm{Z}$ direction of ring gear.

Table 3. Meshing locations and deformation of tooth surface.

\section{(3-1) Ring gear deformation: $263 \mu \mathrm{m}$.}

\begin{tabular}{|c|c|c|c|c|}
\hline Meshing Surface & Meshing Locations & Tooth Surface Stress & Tooth Surface Strain & Tooth Surface Deformation \\
\hline Ring gear & & & & \\
\hline Gear & & & & \\
\hline
\end{tabular}


(3-2) Ring gear deformation: $202 \mu \mathrm{m}$.

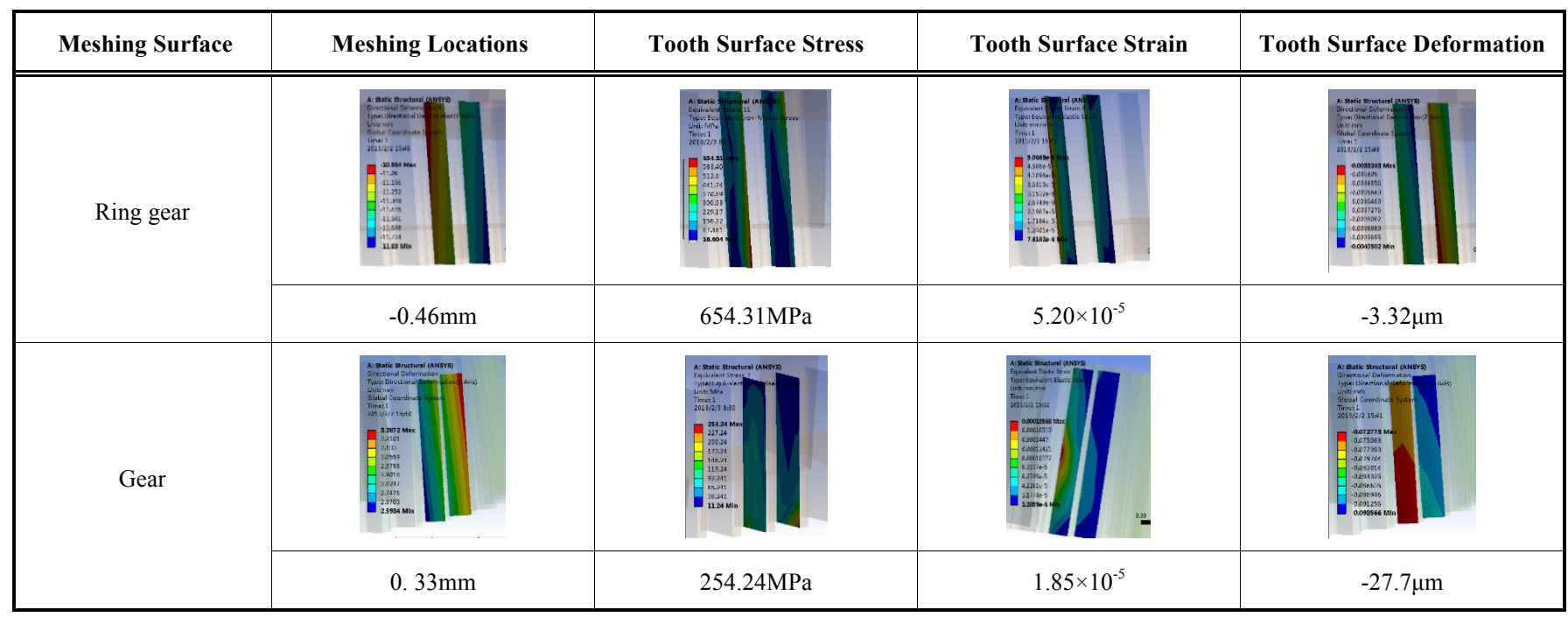

(3-3) Ring gear deformation: $71 \mu \mathrm{m}$.

\begin{tabular}{|c|c|c|c|c|}
\hline Meshing surface & Meshing locations & Tooth surface stress & Tooth surface strain & Tooth surface deformation \\
\hline \multirow[t]{2}{*}{ Ring gear } & 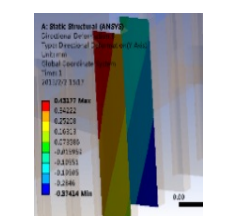 & 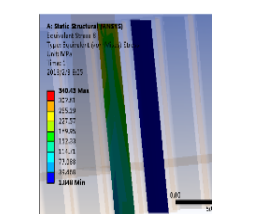 & 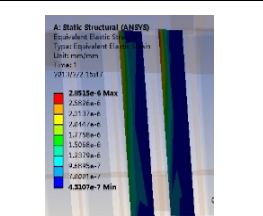 & 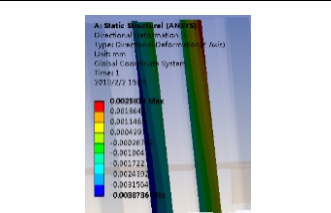 \\
\hline & $0.43 \mathrm{~mm}$ & $340.43 \mathrm{MPa}$ & $0.28 \times 10^{-5}$ & $-2.581 \mu \mathrm{m}$ \\
\hline \multirow[t]{2}{*}{ Gear } & 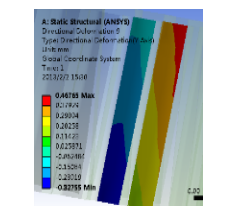 & 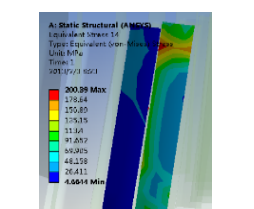 & 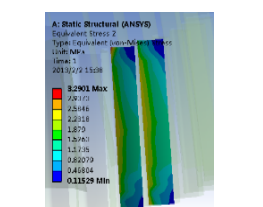 & 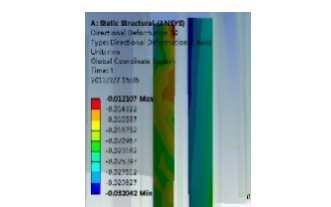 \\
\hline & $0.47 \mathrm{~mm}$ & $200.391 \mathrm{MPa}$ & $1.80 \times 10^{-5}$ & $-12.10 \mu \mathrm{m}$ \\
\hline
\end{tabular}

by the initial meshing stage of the ring gear and other gears having different nature and displacement.

\section{DEFORMATION OF TOOTH SURFACE UNDER THE MESHING EFFECT OF TOOTH-PAIRS EN- GAGEMENT}

By applying the results of Table $\mathbf{1}$ and Table $\mathbf{2}$, the deformation of the meshing among ring gear and other gears with the distortion of the worktable, is analyzed to obtain the results of the deformation of tooth surface and the change of meshing positions under different deformation conditions, as shown in Table 3.

In Table 3, the inhomogeneous deformation of ring gear's assembly changes the positions of meshing force and leads to the deformation field of meshing tooth surface difference obviously. The variation range of total deformation distributed around ring gear is $192 \mu \mathrm{m}$. The variation range of tooth surface meshing's position is more than $1 \mathrm{~mm}$. When the ring gear is meshing, the variation range of tooth surface stress is $314 \mathrm{MPa}$. When two gears are meshing, the variation range of tooth surface stress is $682 \mathrm{MPa}$. The maximum amount of meshing tooth surface's deformation is more than 4 times than the minimum one.

This result indicates that the inhomogeneous deformation caused by ring gear's assembly makes the deformation field unstable under the effect of worktable's distortion. Furthermore, the deformation field and the meshing positions of gear and ring gear change continuously, which leads to the accuracy of continuous tooth-pairs engagement, the positioning accuracy and the repetitive positioning accuracy of worktable declining.

\section{CONTROLLING METHOD OF RING GEAR'S AS- SEMBLING DEFORMATION}

According to the analysis results of ring gear's distortion, deformation field of meshing tooth surface and the meshing position, aiming at the structural characteristics and material 


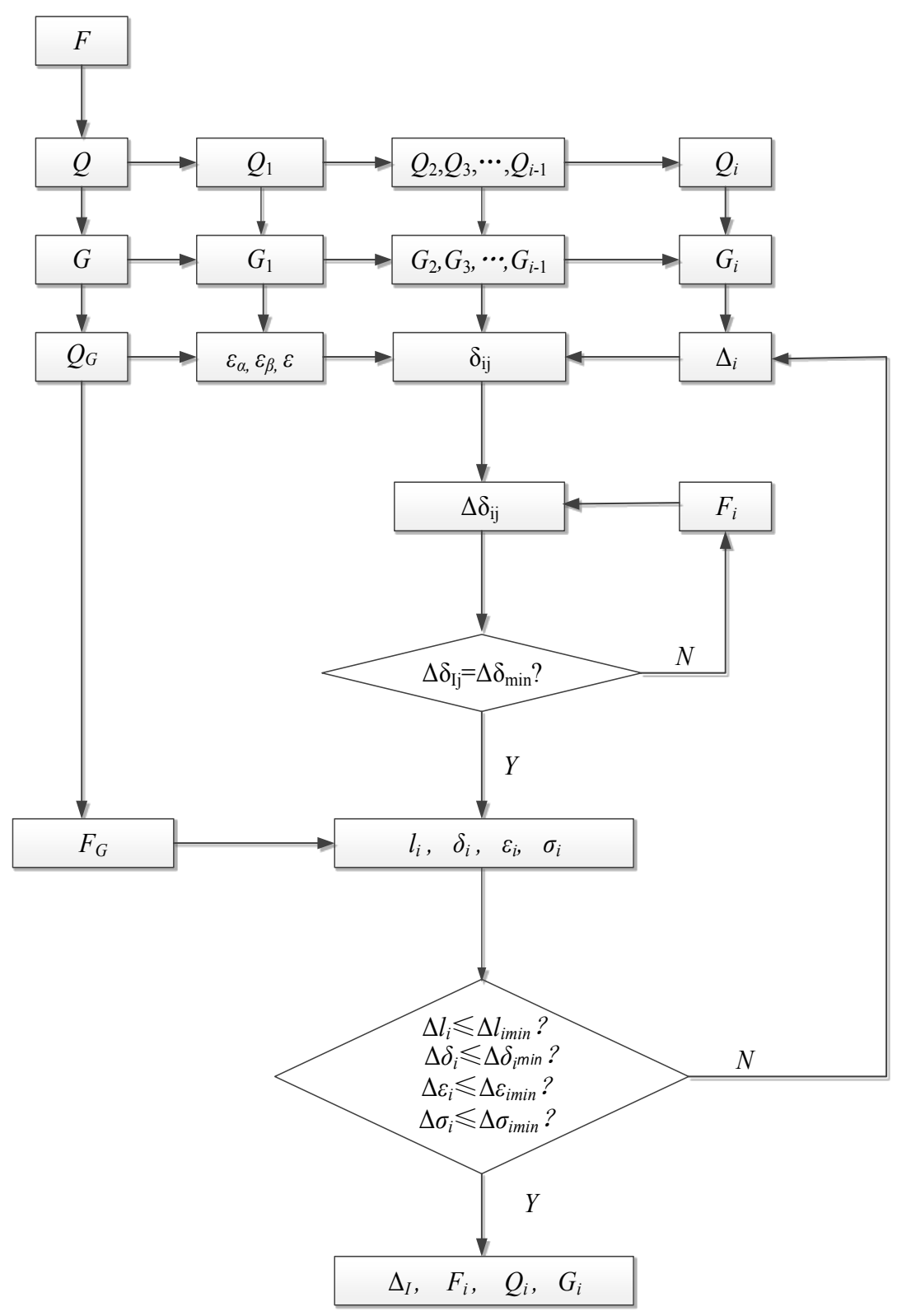

Fig. (6). Controlling method of ring gear's assembling deformation.

properties of ring gear and worktable, the influence of gear surface's hardness on the ring gear's assembly deformation is adopted to guarantee the worktable's rotary precision and indexing precision, so as to meet the requirement of the contact stiffness, the friction factor, the assembling preload force and the assembling interference amount. Finally, the design method is put forward, which is about controlling the pretightening force of ring gear's assembly inhomogeneous deformation and the assembling interference amount, as shown in Fig. (6).

In the picture, $F$ is press force. $F_{i}$ is assembly preload force. $F_{G}$ is working load of worktable. $Q$ is assembly process variable of ring gear. Q1 is structural parameters of ring gear. $Q_{2} \sim Q_{i-1}$ are ring gear's material and physical function parameters respectively. $Q_{i}$ is ring gear's error. $G$ is assembly process variable of worktable. $G_{l}$ is worktable's structure parameters. $G_{2} \sim G_{i-1}$ are worktable's material and physical function parameters respectively. $G_{i}$ is worktable's error. $Q_{G}$ is assemblies of ring gear and worktable. $\varepsilon_{\alpha}$ is transverse coincidence degree between ring gear and worktable. $\varepsilon_{\beta}$ is vertical coincidence degree between ring gear and worktable. $\varepsilon$ is total coincidence degree. $\Delta_{i}$ is shrink range of assembly. $\delta_{i j}$ and $\Delta \delta_{i j}$ is ring gear's assembly deformation and its changing range respectively. $\Delta \delta_{\min }$ is the minimum changing range of ring gear's assembly deformation. $l_{i}$ and $\Delta l_{i}$ is the position of tooth surface meshing and its variation quantity respectively. $\Delta l_{\min }$ is the minimum changing range of tooth surface meshing's position. $\delta_{i}$ and $\Delta \delta_{i}$ is end deformation amount and its changing range respectively. $\Delta \delta_{\min }$ is minimum changing range of the end deformation amount. $\varepsilon_{i}$ and $\Delta \varepsilon_{i}$ is the strain of tooth surface and its deformation amount respectively. $\Delta \varepsilon_{\min }$ is the minimum changing range of tooth 


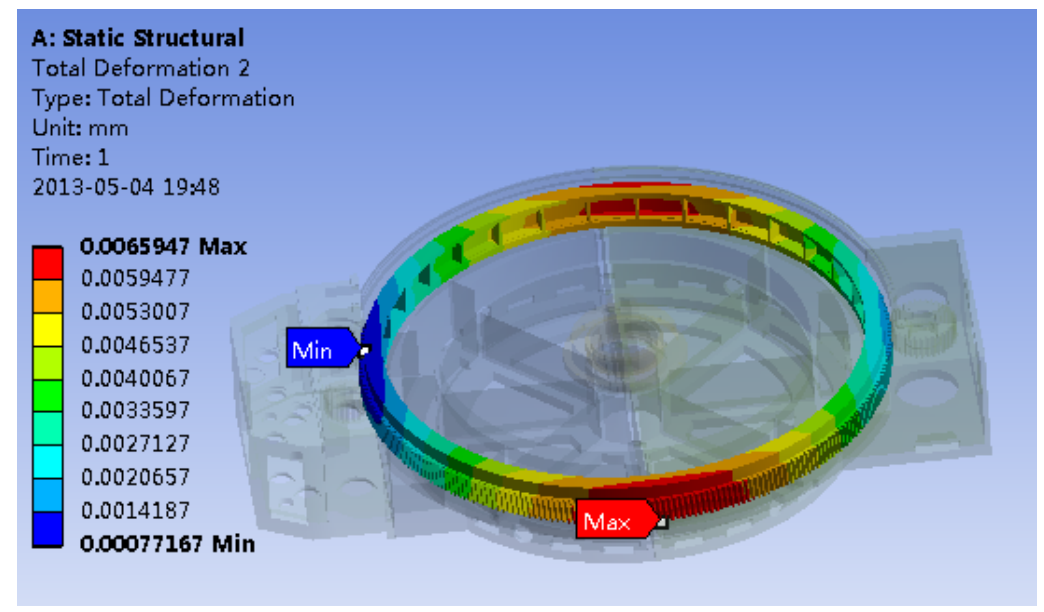

Fig. (7). Deformation field of ring gear.
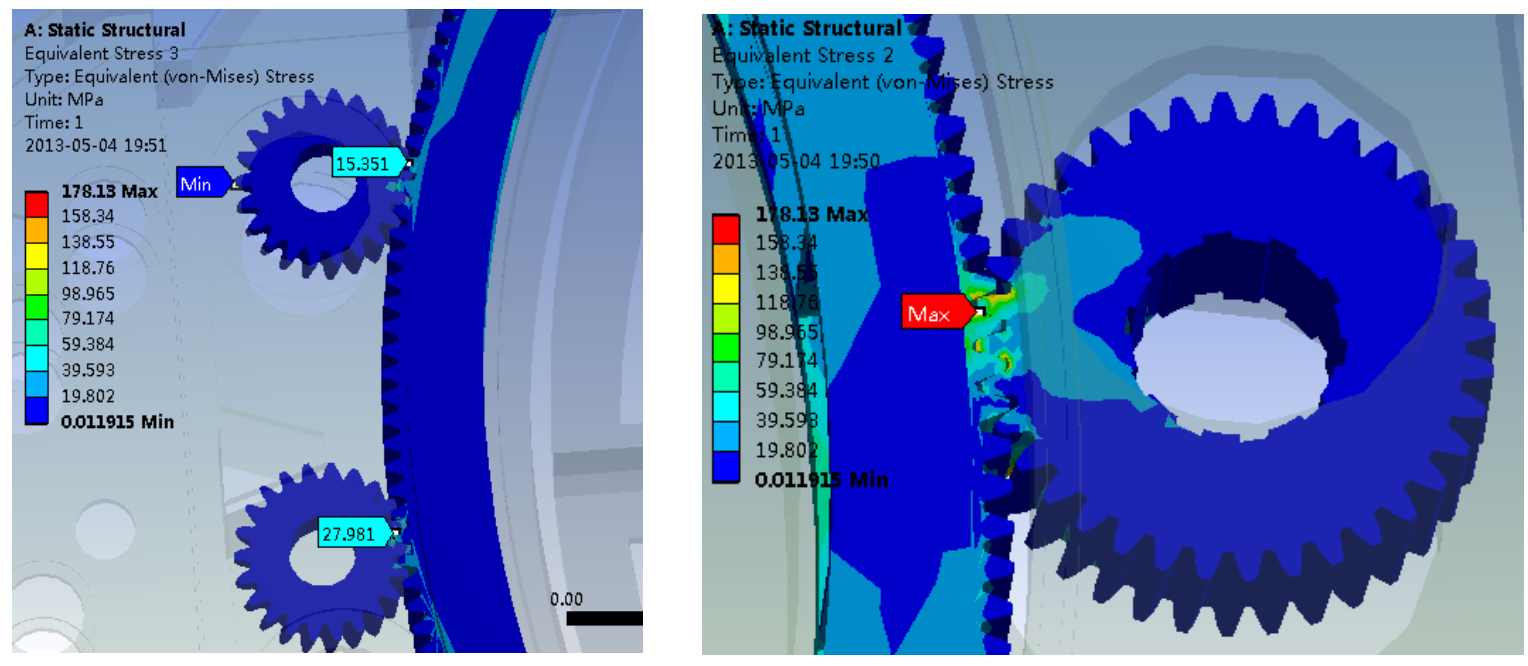

Fig. (8). Deformation field of meshing of tooth-pairs.

surface's strain. $\sigma_{i}$ and $\Delta \sigma_{i}$ are tooth surface's stress and its deformation amount respectively. $\Delta \sigma_{\text {min }}$ is the minimum changing range of tooth surface's stress.

The method mainly aims at the error distribution of joint surface. The preload force of 32 screws, the assembly preload force and assembly interference amount of ring gear are changed to improve its inhomogeneity of deformation field and make the meshing position in a stable state as shown in Fig. (7) and Fig. (8).

The analysis results show that the range of assembly deformation amount of ring gear can be controlled within $50 \mu \mathrm{m}$, the stress range of the meshing tooth surface between the ring gear and other three gears is $178 \mathrm{Mpa}$ and the range of meshing tooth surface position is less than $0.06 \mathrm{~mm}$. The stability of deformation field distributed around the ring gear and the stability of the deformation field in continuous meshing state can be improved significantly.

Taking advantage of the above methods, the assembly of ring gear has been conducted. The assembly process and its results are shown in Fig. (9) and Fig. (10).
$P_{1}, P_{2}$ are left body and right body of worktable separately, $P_{3}$ is positioning and clamping device of worktable assembly, $P_{4}$ is ring gear, $P_{5}$ is assembly positioning and clamping device of gear ring, $P_{6}$ is bearing sleeve, $P_{7}$ is worktable assembly, $P_{8}$ is the assembly body of ring gear and worktable, $P_{9}$ is ring gear assembly deformation adjustment, $P_{10}$ is worktable installation.

The test results of the assembly of the ring gear and the gears show that the coaxial degree of gear tooth pitch is less than $0.03 \mathrm{~mm}$ and the contact surface area of the assembly joint surface between ring gear and other three gears is more than $85 \%$, so the gears and the ring gear could move flexibly and smoothly. After the worktable assembly, the test results of precision index shows that the worktable's positioning accuracy is $28^{\prime \prime}$, the one-way repeated positioning accuracy is $8^{\prime \prime}$, the reverse difference is $12^{\prime \prime}$, the bi-directional positioning system deviation is $20^{\prime \prime}$, the two-way average position deviation is $12^{\prime \prime}$ and the positioning accuracy and repeat positioning accuracy of worktable meet the design requirements of CXK5463 turning-milling machining center of gantry moving type. 


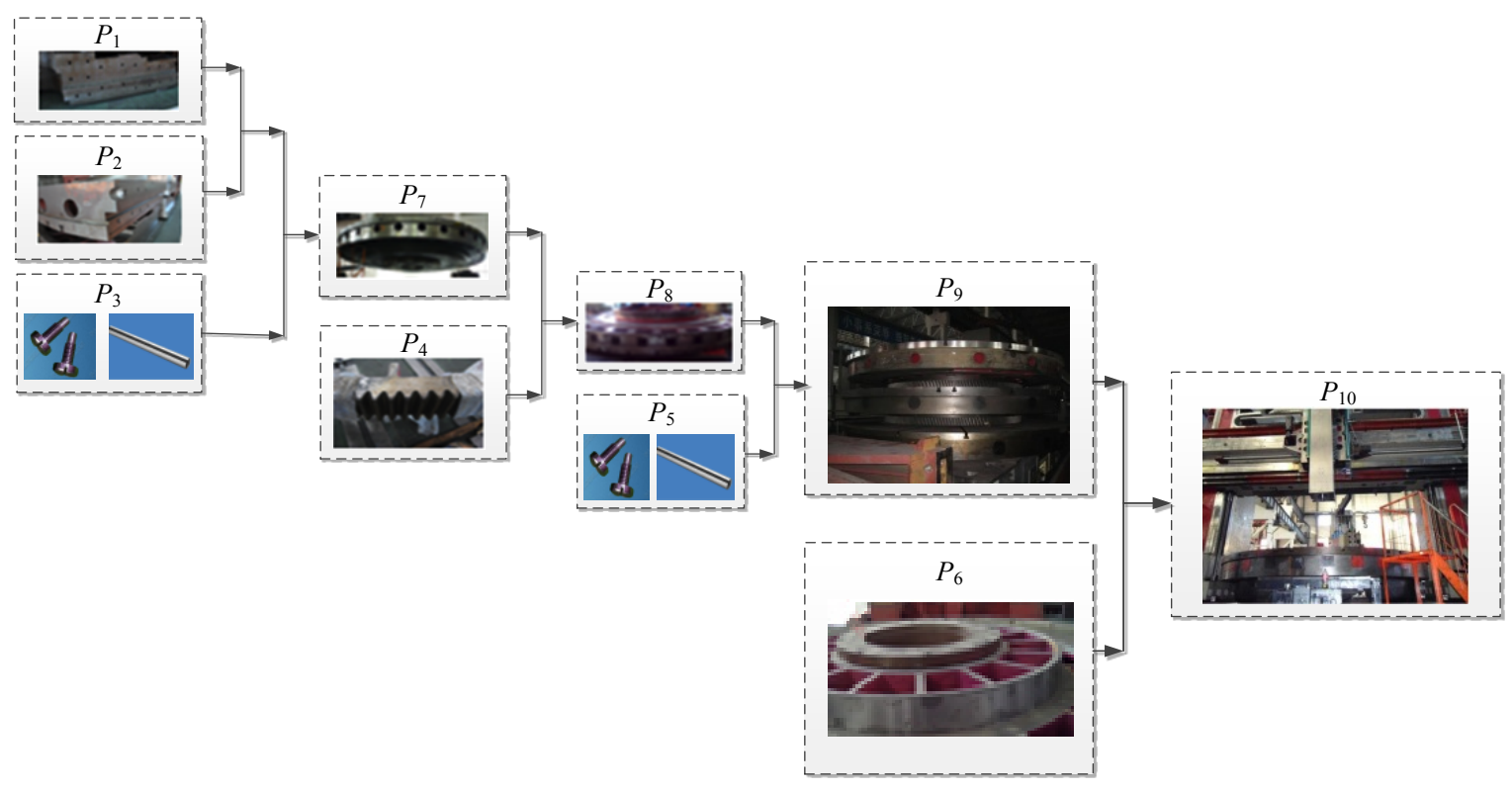

Fig. (9). Assembly process of ring gear.
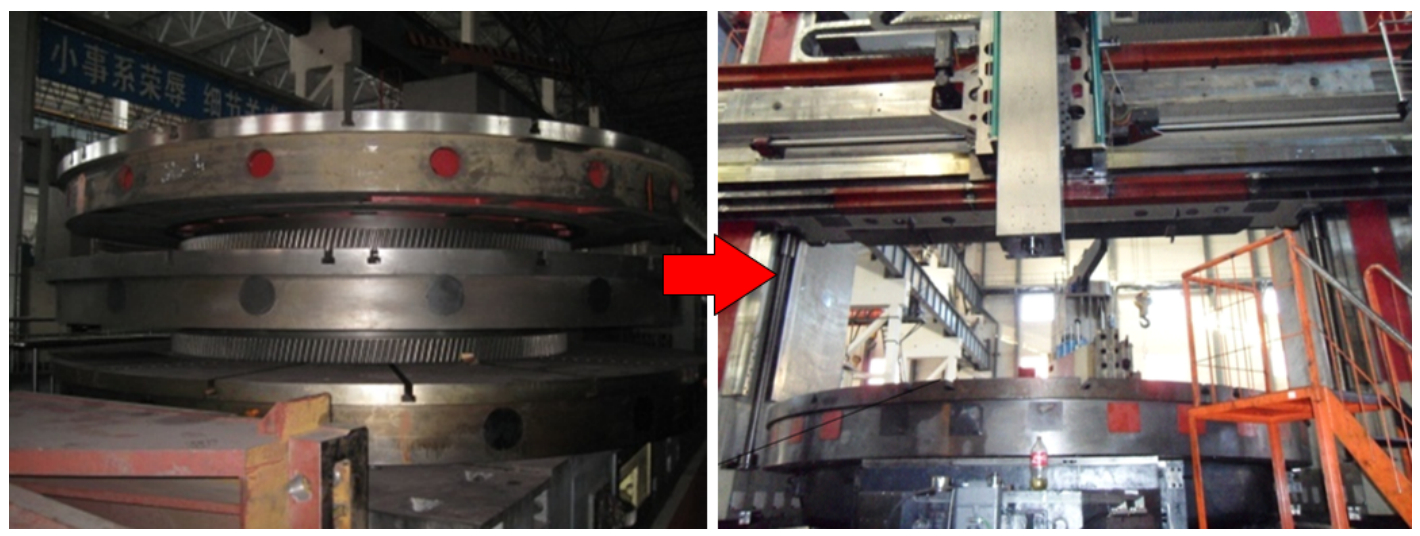

Fig. (10). Assembly result of ring gear.

\section{CONCLUSION}

Using the meshing relation between the ring gear and the anti-backlash gear and the one between the ring gear and the drive gear, the circumferential force, the radial force, the axial force, the normal force, the friction meshing with the gears and the transverse coincidence degree under the maximum torque are obtained. Furthermore, the boundary conditions of the deformation field of the ring gear assembly and tooth-pairs engagement are ensured.

Under the press-fit force of $20 \mathrm{KN}$, the inhomogeneous deformation phenomenon appears in the assembly process of the ring gear and the worktable, which leads to the acting area of meshing force changing in a wide range and makes the deformation field of meshing tooth surface unstable. The inhomogeneous deformation of ring gear assembly is an important factor causing the decline of the transmission accuracy and its stability of ring gear and meshing tooth surface.
Taking advantage of the influence of tooth face hardness, contact stiffness, friction coefficient, assembly preload force and assembly magnitude of interference on the ring gear assembly deformation, the assembly preload force of the ring gear and the distribution of magnitude of interference are modified with adjusting 32 pretightening force of screws. The variation range of ring gear assembly can be controlled in less than $50 \mu \mathrm{m}$ which indicates that the deformation fields of ring gear assembly and tooth surface meshing have been improved.

The results of ring gear assembly and worktable accuracy detection show that in the approach of controlling ring gear's non-uniform deformation, the contact surface area of the assembly joint surface between ring gear and the three gears is more than $85 \%$. The three gears and the ring gear transmit flexibly and smoothly and the accuracy test results of the positioning accuracy and the reorientation positioning accuracy meet the design requirements. 


\section{CONFLICT OF INTEREST}

The authors confirm that this article content has no conflict of interest.

\section{ACKNOWLEDGEMENTS}

This work was supported by National S \& T Major Project (2011ZX04002-111)

\section{REFERENCES}

[1] H.L. Liu, B. Li, H.M. Shi, and H.Q. Liu, "Method of position accuracy determination and position error compensation of embedded CNC machine tools", Journal of Huazhong University of Science and Technology (Natural Science Edition), vol. 32, pp. 31-33, 2004.

[2] H.L. Liu, H.M. Shi, B. Li, and H.C. Zhou, "Relay method: geometric error measurement of planes on CNC machine tools", Journal of Huazhong University of Science and Technology (Natural Science Edition), vol. 33, pp. 60-62, 2005.

[3] Z.P. Guo, Z.Y. Song, and R.B. Shi, "Error source identification of machining accuracy of five-axis linkage CNC machine tools", $A d$ vanced Materials Research, vol. 846-847, pp. 34-39, 2014.

[4] J.H. Zhang, "The analysis and measurement of three-coordinate CNC machine tool motion", Mechanical Engineer, vol. 9, pp. 2122, 2005.
[5] X.L. Cui, X.H. Liu, and G.M. Guo, "Study on assembly sequence planning method based on subassembly", Modular Machine Tool \& Automatic Manufacturing Technique, vol. 5, pp. 78-81, 2012.

[6] F. Zhao, X.G. Zhou, S. Ai, and X.B. Zhou, "Study of green manufacturing technology based on modal testing of machine assembly sequence", Manufacturing Technology \& Machine Tool, vol. 12, pp. 73-78, 2012.

[7] S. H. Qiu, B.C. Wu, and C. Su, "Made CNC machine tools to improve the reliability of the current situation and countermeasures", Manufacture Information Engineering of China, vol. 13, pp. 1-4, 2009.

[8] J.Y. Zhao, "The evaluation and improvement paths of the reliability of numerical control machine", Sci-Tech Information Development \& Economy, vol. 11, pp. 143-145, 2009.

[9] X.Z. Wang, Y. Li, and G.H. Cheng, "Calculation method for kinematical accuracy reliability of main drive mechanism of diesel engine", Transactions of the Chinese Society of Agricultural Engineering, vol. 4, pp. 184-185, 2011.

[10] J.B. Song, H.Z. Liu, D.N. Yuan, Z.Y. Wu, and J.P. Wang, “Accuracy reliability of transmission system for numerical control machines”, China Mechanical Engineering, vol. 7, pp. 785-786, 2011.

[11] G.Q. Guan, "The spindle assembly process design of a highprecision CNC lathe", Manufacturing Technology \& Machine Tool, vol. 1, pp. 45-47, 2012.

(C) Bin et al.; Licensee Bentham Open.

This is an open access article licensed under the terms of the Creative Commons Attribution Non-Commercial License (http://creativecommons.org/licenses/by$\mathrm{nc} / 4.0 /$ ) which permits unrestricted, non-commercial use, distribution and reproduction in any medium, provided the work is properly cited. 